\title{
Entrepreneurial Intentions Among Business Students in Pakistan
}

\author{
Abdullah Azhar, Annum Javaid, Mohsin Rehman and Asma Hyder \\ NUST Business School, Pakistan
}

\begin{abstract}
The present exploratory study is based on the 'Entrepreneurial Intention Model' and has its foundation in 'Planned Behavioural Theory'. The main focus of the study is on measuring factors affecting Entrepreneurial Intentions among business students in Pakistan. Apart from demographics, the study is particularly focused on personal attraction, perceived social norms and perceived social behaviour. The paper is based on systematic sampling methodology and targets business graduates and nascent entrepreneurs. The study will provide useful implications for educational institutions within the field of business and management, and off course for government policy makers.
\end{abstract}

\section{Keywords}

Entrepreneurship, entrepreneurial intention, behavioural variables, Business Studies

\section{Introduction}

Today entrepreneurship has become one of the most critical activities for the development of any economy. Reason for this importance is that growth of entrepreneurial activities lead to creation of opportunities for the various sectors of the society. Entrepreneurial activities generate job opportunities and multiple other economic benefits. This happens because in economic terms entrepreneurial activity is the combination of risk taking and innovation. So such activities lead to new businesses offering innovative products and services, which eventually lead to a significant contribution to the development of the economy.

In an under developed country like Pakistan, importance of entrepreneurship grows by many fold. However, unfortunately Pakistan's economy is severely lacking in such activities. There are multiple reasons for this which includes both psychological and hardcore factors. In Pakistan, only government is expected to take initiatives and for the setup of new establishments. Thus in order to encourage entrepreneurial activities in Pakistan, it is imperative that along with modifying the Mercantilist role of government, ideology and behaviour of people also needs to be altered as well.

Copyright (C) 2010 Victoria University. This document has been published as part of the Journal of Business Systems, Governance and Ethics in both online and print formats. Educational and non-profit institutions are granted a nonexclusive licence to utilise this document in whole or in part for personal or classroom use without fee, provided that correct attribution and citation are made and this copyright statement is reproduced. Any other usage is prohibited without the express permission of the publisher.
Schumpeter tersely defined different function and activities that entrepreneurs play in an economy. Schumpeter in theory of business enterprise proclaimed that entrepreneur is pecuniary, hence from a neoclassical viewpoint this explains entrepreneur as a capitalist and profit oriented. Nevertheless pecuniary has less to do with profit motives. In Mark I theory (1911) Schumpeter claimed that changes in

1

Azhar, A, Javaid, A and Rehman, M are graduating students and Dr Asma Hyder is Assistant Professor at NUST Business School, Islamabad. The authors are thankful for encouraging remarks given by Dr Ather Maqssod Ahmed. Authors are also thankful to anonymous referees of the Journal for useful comments; however authors remain responsible for any errors in the paper. 
shape of technology or innovation are led by entrepreneurs. Later, Mark II theory states that players contributing to innovation and economy are usually big organizations with proper resources and capital.

The main focus of this study is to measure how different factors influence 'Entrepreneurial Intentions' among the business students or young graduates those who are about to enter in the labour/ job market. For this selected behavioural variables; entrepreneurial knowledge, professional attraction, social valuation, entrepreneurial capacity, entrepreneurial capacity are used as determinants of entrepreneurial intentions among young entrepreneurs. Apart from these behavioural variables demographics and father's education is also included the estimated model. The study aims to provide useful implications for educational institutions within the field of business and management, and for government policy makers.

Now the scheme of the study is outlined. Introduction is followed by the section two which is Literature Review. Third section is of Data that describes sample properties and questionnaire. Model and Methodology is the fourth section that comprises of the model used for the research. Section five is based on discussion and analysis of the results obtained. Finally the paper ends with the conclusion.

\section{Literature Review}

A huge amount of literature is available on the subject topic. However this study is restricted on few important, most relevant and interesting studies. Bird (1988) identified variables which characterize the entrepreneurial climate - willingness to take risks and accept the possibility of failure, the level of difficulty associated with the initiation and growth of a start up, level of respect given to people involved in the entrepreneurial activities and the socialization; the study explain that these variables differ among individuals. The study also emphasized that success rate of startups and number of large firms in the society influences the entrepreneurial behaviour. Similar findings are found by Jackson \& Rodkey (1994). Later on, literature also highlight that values, behaviours and traits are very significant determinants in setting up the entrepreneurial environment [Jesselyn Co and Mitchell (2005)]. The comparison of two different theories in the subject, i.e., 'Entrepreneurial Event' [Shapero \& Sokol, (1982)] and 'Planned Behaviour' [Ajzen (1991)] presented by Linan et al. (2005) and further found that salaried job preference negatively relates with entrepreneurial intention while with respect to some socio-demographic predominantly gender, has a significant impact on intention. Similar work has been done by Linan and Santos (2007) in entrepreneurs' intentions.

The individuals who want to become entrepreneurs are motivated by both intrinsic and extrinsic rewards. The barriers on the other hand are lack of capital, skills, confidence and compliant cost etc Wong \& Choo (2006). Based on the same idea Schoof (2006) also explored the same issue and concludes that social/cultural attitude towards youth entrepreneurship, entrepreneurship education, access to finance/start-up financing, administrative/ regulatory framework and business assistance/support are the significant barriers in starting up a new business.

Rommi (2005) analysed women entrepreneurs in Pakistan by developing a greater understanding of women belongs to different cultural background, presenting gender-related challenges and opportunities. A important study carried out in Pakistan is by Haque (2007) concluded that for amplifying entrepreneurial base in the country, government reform to limit rent-seeking, encourage innovation and to foster enterprise are essential and proposed the strategy for a new growth and empowerment of cities might be the fundamental steps. Chemin (2008) analysed the role of government policies in Pakistan for SMEs. The paper emphasized the factors such as workers employment, credit acquisition, taxes payment and enforcement of contracts further obstacle the upbringing of entrepreneurs in Pakistan.

Basu and Virick (2008) evaluated entrepreneurial intentions and their antecedents. Their findings highlight that education and prior experience does have a positive and significant impact on entrepreneurial behaviour. Nasurdin, Ahmad and Lin (2009) in their research tested a causal model and examined the effect of factors like role model, social identification, and social norm and perceived desirability on entrepreneurial intention in Malaysia. 


\section{Data}

Entrepreneurial activities plays very important role in economic growth and development. Several studies have identified entrepreneurship as a critical factor in the economic growth and development of nations (Birley, 1987; Reynolds, 1987; Morris \& Lewis, 1991; Shane, Kolvereid, \& Westhead, 1991). Young entrepreneur can play an important role in improving the entrepreneurial activities in a country. The encouragement and provision supporting environment and institutions are important for young entrepreneurs so that they can start and take a step toward establishing their own set-up. This would be helpful in reducing queues for employment and generate the economic activity in the society. In Pakistan many institutions are providing entrepreneurial education and many graduates are produced every year in business administration but still the country has not achieved a significant level of economic activity.

Thus this study is based on information gathered from young graduates in business studies to explore the facts about hindrances in entrepreneurial activity. Since study is focused on nascent entrepreneurs the data collected for the study is based on stratified sampling from seven public and private universities located in twin cities, i.e, Rawalpindi and Islamabad. The strata's are constructed based on geographical basis so that all areas of two cities can be covered properly. The universities considered are those recognized by Higher Education Commission.

For the analysis the study focused only final year students, our target sample are serious students with some prior knowledge of business. Basu and Virk (2008) emphasized in their study on the argument those students who had prior entrepreneurship education have a positive attitude towards a career in entrepreneurship. Since business students get relatively higher exposure to entrepreneurial activities and education, the response rate of data selection is $85 \%$ out of 376 students surveyed.

For our study we used Entrepreneurial Intention Questionnaire ${ }^{2}$ which has been previously used in many studies $^{3}$ and was actually designed by Linen (2005). This questionnaire assesses the entrepreneurial intention based on eight properties which include Education and experience, Entrepreneurial knowledge, Professional attraction, Social valuation, Entrepreneurial capacity, Entrepreneurial intention, Entrepreneurial objectives and Entrepreneurship education. Apart from these variables demographics are also included in the analysis. The questionnaire utilized is included 2 in Annexure. All of these variables have been measured using Likert- type scale.

\section{Model and Methodology}

The questionnaire used in the study has various factors which together measure the entrepreneurial intention among young individuals who are about to graduate and have plans to start their own establishments. The variables that are in the questionnaire are as follows and discussed below:

\subsection{Education and Experience}

This variable measures the education level of the respondents and the degree they want to complete, when they expect it to finish and which factors influenced them to take it. Further, it measures the work experience if any.

\subsection{Entrepreneurial Knowledge}

This variable measures the entrepreneurial knowledge the respondents have and whether they know any entrepreneur in their family, friends or acquaintances. Moreover, it measures the extent of knowledge on some particular aspects related to starting a firm.

The questionnaire is not attached with the study, however can be provided on request.

Linan, F., Rodriguez-Cohard, J.C., \& Guzman, J. (2008). Temporal Stability of Entrepreneurial Intentions: A Longitudinal Study. Paper presented at $4^{\text {th }}$ European Summer University Conference on Entrepreneurship, Bodø, Norway, 22nd to 26th August 2008. 


\subsection{Professional Attraction}

Professional Attraction captures the respondent's career plans, the type of profession they would choose based on external environment from medium to long term perspective and whether becoming an entrepreneur attracts them or not.

\subsection{Social Valuation}

The social valuation seeks to find out whether being an entrepreneur is valued more than other professions and careers in the close social network of the respondent. Furthermore, it tries to find out how acceptable it is by the society to become an entrepreneur.

\subsection{Entrepreneurial Capacity}

Entrepreneurial capacity highlights respondent's aptitude to start any entrepreneurial project or a firm. Additionally it entails ability to effectively manage and monitor the project. For this reason an individual's characteristics such as opportunity recognition, creativity, innovation, problem solving, communication and networking are being analyzed.

\subsection{Entrepreneurial Intention}

This variable examines how much a respondent is interested to be an entrepreneur either in present scenario or may be some time later in future. In essence the level of determination of choosing entrepreneurship as a career is gauged.

\subsection{Entrepreneurship Education}

Entrepreneurship Education evaluate the depth of knowledge a respondent has about entrepreneurial environment, required abilities, recognition of the entrepreneur's figure and the intention to be an entrepreneur, by taking an entrepreneurship course. It further examines the level awareness that can be developed by taking relevant courses.

The model use to evaluate entrepreneurial intention can be written as follows:

Entrepreneurial Intention $=\boldsymbol{f}$ (Demographics, Experience, Entrepreneurial Knowledge, Professional Attraction, Social Valuation, Entrepreneurial Capacity, Entrepreneurial Intention, Entrepreneurship Education) or

EI $=\alpha+\beta_{1}$ Gender $+\beta_{2}$ Age $+\beta_{3}$ Father's Education $+\beta_{4}$ Father's Employment $+\beta_{5}$ Exp $+\beta_{6}$ EK + $\beta_{7} \mathbf{P A}+\beta_{8} \mathrm{SV}+\beta_{9} \mathrm{EC}+\beta_{10} \mathbf{E E}+\varepsilon$

Where:

Dependant Variable

$\mathrm{EI}=$ Entrepreneurial Intention

Independent Variables:

Gender $=1$ if male

$=0$ if female

Age $=$ Age of the respondent measured in years

Father's Education = Respondent's father's years of schooling

Father Employment $=$ Four dummies are introduced to capture the effect of father's employment status

$=1$ if father employed and zero otherwise

$=1$ if father self-employed and zero otherwise

$=1$ if father unemployed and zero otherwise (this category has been used as reference group in the regression analysis)

The independent variables include Exp, EK, PA, SV, EC, EE these variables are abbreviated by Experience measured in months, Entrepreneurial Knowledge, Professional Attraction, Social Valuation, Entrepreneurial Capacity and Entrepreneurship Education. $\alpha$ and $\varepsilon$ are intercept and error terms respectively. 
To estimate the equation (1) the study is relying on Ordinary Least Square method. Few studies employed simultaneous equation method or other econometric techniques. The study equation (1) fulfils all the assumptions of the ordinary least square. The estimated results are presented in following sections.

\section{Discussion and Analysis}

Now the results are discussed in order.

\subsection{Reliability Analysis}

The questionnaire used for this study has been developed in Spain and later on used after checking the reliability and validity in Spain, Taiwan, Brazil and Korea. Culture is an important component of entrepreneurship or establishment of new set-ups Hofstede (1980) but this study is very initial step toward exploring the business intentions in Pakistani environment thus it do not attempt to address the cultural sensitivity analysis. To examine the reliability of the questionnaire in different environment the study calculated the Chronbach alpha's. All the alpha's meet the required criteria except the variable "social valuation" that is comparatively low. However this study does not attempt to develop new scale to capture this particular variable. Moreover some studies [for example: McGrath, MacMillan, and Scheinberg (1992) found that entrepreneurs share a common set of values despite differences in cultural background.

The values for Cronbach's Alpha are presented in Appendix Table 5.1. Reliability coefficient of .70 or more is regarded as "adequate" in most research situations [Nunnally (1978)]. The test reveals that value of Cronbach's Alpha for variables including entrepreneurial knowledge, professional attraction, entrepreneurial capacity, entrepreneurship intention and entrepreneurial education have high internal consistency as their respective values are higher than 0.8 . However one variable i.e. Social Valuation is having a low internal consistency as its value is 0.64 . The low value of Cronbach Alpha for Social Valuation is probably due to differences in culture. However the study is stick to using the same items for this analysis.

\subsection{Summary Statistics}

Appendix Table 5.2 presents the summary statistics of data used in the study. Survey results have shown that on average thirty percent of the respondents have work experiences. The average age of sample came out to be almost twenty two years and it comprised of about sixty percent male. While on the education scale we found fathers to be more literate than mothers result revealed that average education of father is university and that of mother is Higher Secondary. Sixty one percent of the respondent's fathers are employed either in public and private sector, while twenty one percent of them are entrepreneurs. On the basis of Likert Scale ranging from one to seven average score for entrepreneurial knowledge is 4, professional attraction 4.6, social valuation 4.2, entrepreneurial capacity 4.3, entrepreneurial intention 4.3 and entrepreneurial education 4.8. That shows the average response on the behavioural variables.

\subsection{Pearson Correlation}

The Pearson Correlation is calculated only among the behavioural variables. The results are presented in Appendix Table 5.4. The purpose of presenting Pearson Correlation estimates is to confirm the relationship and relevance of variables with each other. All the variables are significantly related to each other but low magnitude of relationship confirms the absence of multicollinearity. Later on before estimation of regression analysis we checked the assumption of multicollinearity and found that there is no multicollinearity among independent variables. Only the social valuation has an insignificant relationship with Entrepreneurial Intention. The strongest correlation of Entrepreneurial Intentions is found to be with Personal Attraction. The detailed discussion of results will be provided in the regression analysis section. 


\subsection{Regression Analysis}

The results of regression analysis are presented in Appendix Table 5.3. Over all the estimated model gives a good fit. This value of R-Square is comparatively low but this is quite acceptable for crosssection data [see Kmenta (1997)]. The estimated co-efficient are discussed below in order.

Starting from gender, the estimated results show that being male increase the entrepreneurial intentions. Gender is entered as dummy variable in our regression equation; the estimated results show that male business students have .61 percentage points more entrepreneurial intention as compared to female business students. Among Pakistani households the role of male and female members are usually predetermined. Females are responsible for household responsibilities and male members are responsible for bread earning. Thus within Pakistani perspective this result is quite obvious. However, the age and experience are insignificant but have positive relationship in regression analysis. Parental background is insignificant in the regression equation estimation. The reason might be that business students are sometimes not very influenced with their parental work experience especially during the initial time period of starting the practical life. Many business students are not from families with business background.

All the behavioural variables are significant at conventional level and have positive relationship with entrepreneurial intention. Among all the behavioural categories professional attraction is most influential factor on the entrepreneurial intention and it is closely followed by entrepreneurial capacity. Since this study is based on perception of young people those who are about to enter in labour market. At this stage in life students are attracted toward starting their own business not only because of their interest and ambitions in life but also because of desperate condition of availability of jobs in the market. In addition to this entrepreneurial education and gender also depicted a strong relation with the aim of becoming an entrepreneur. At the same time social valuation has the most noteworthy negative relationship with entrepreneurial intention. The Pakistani households are usually characterized as risk averse and socially it is considered embarrassing if their children or any member of the household is starting or establishing a small business like opening a shop etc. Moreover decision of career selection is not only individual's decision but many social pressures are negatively or positively influencing on it. Results for correlation statistics are presented in Table 5.4. For the correlation coefficients it has been found that most significant relationship of Entrepreneurial Intention is with professional attraction which is followed by entrepreneurial capacity and entrepreneurial education. Entrepreneurial knowledge is insignificant which shows the lack of awareness among nascent entrepreneurs; they don't have ideas about the type of business they should start, how and from where to start. This also points toward the education that is provided in educational institutions which lacks in provision of such information.

Significance of entrepreneurial intention was advocated by Linan and Cohard (2008) as well. They concluded that entrepreneurial intention as one of the strongest predictor for start up decisions. In addition to this with their longitudinal study they found that in order to encourage entrepreneurial acidities socialization of young graduates is important. Linan and Chen (2006) stated that social aspects have an insignificant effect on the process from perceptions to intentions. However we have found different results in Pakistan, as our research shows that many of the young people were not willing to opt for entrepreneurial activities, just because it was not socially admired. Thus it means that social norms and admiration significantly influences entrepreneurial intention in Pakistan.

\section{Conclusion}

On the basis of our research we came to the conclusion that there exists a strong positive correlation between entrepreneurial intention and professional attraction. On the other hand social valuation is negatively correlated to entrepreneurial intention. Thus the results convey this message that in order to develop a healthy entrepreneurial climate in the country, it is required that current entrepreneurs must be appreciated and awareness about the benefits of entrepreneurship must be created among individuals. Our results imply that even in the presence of entrepreneurial attraction, lack of proper platform hinders the intentions of entrepreneurial activities in the country. This leads towards very 
important policy implication for institutionalization of starting a business or establishment of new setups.

On the psychological side it is important that entrepreneurship must be made socially attractive so that instead of preferring jobs, people take initiatives of launching their own businesses. In Pakistan generally people are risk averse while growth of entrepreneurship has a very strong relationship with the risk taking ability. Thus in order to promote entrepreneurship people must be provided proper consultancy and platform so that they have a sense of security. While on the tangible grounds it is important that role of SME (Small and Medium Enterprises) and SMEDA (Small and Medium Enterprises Development Authority) must be made much more effective and communication gap between them and general public must be reduced.

The present study is an attempt to measure the entrepreneurial intention admitting the fact that there is dearth of research on the subject topic. But this study is not without limitations. First the variable 'Social Valuation' needs to modify in terms of items in questionnaire. Second the study is based on cross-section data and can be converted into longitudinal study.

\section{References}

Basu, A., \& Virick, M (2008) .Assessing Entrepreneurial Intentions Amongst Students: A Comparative Study, Peer Reviewed Paper, San Jose State University.

Bird, B. (1988). Implementing Entrepreneurial Ideas: The Case for Intention. The Academy of Management Review, Vol. 13(3). Pp. 442-453.

Birley, S. (1987). New ventures and employment growth. Journal of Business Venturing, 2(2), 155 165.

Chemin, M. (2008). Entrepreneurship in Pakistan: Government Policy on SMEs, Environment for Entrepreneurship, Internationalization of Entrepreneurs and SMEs. Department of Economics, University of Quebec at Montreal (Canada), 31 March.

Co, J.M., \& Mitchell, B. (2005). An Analysis of Cultural Factors Affecting Entrepreneurship in the Philippines. University of Greenwich Business School, London.

Haque, N. (2007). Entrepreneurship in Pakistan. Pakistan Institute of Development Economics. Working Papers 2007:29 Islamabad, Pakistan.

Hofstede, G. (1980). Culture's Consequences: International Differences in Work-Related Values. Beverly Hills, CA: Sage.

Jackson, J.E., \& Rodkey, R.G. (1994). The Attitudinal Climate for Entrepreneurial Activity. The Public Opinion Quarterly, Vol. 58(3). Pp.358-380.

Linan, F., \& Santos, F.J. (2007).Does social capital affect entrepreneurial intentions? International Advances in Economic Research, Vol 13(4). Pp 443-453.

Linan, F., Rodriguez-Cohard, J.C. \& Rueda-Cantuche, J.M. (2005). Factors affecting entrepreneurial intention levels, 45th Congress of the European Regional Science Association, Amsterdam, 23-27 August.

McDaniel, B. A. (2005). A Contemporary View of Joseph A. Schumpeter's Theory of the Entrepreneur. Journal of Economic Issues, Vol. 39, Issue 2, Pp 485-489.

McGrath, R.G., MacMillan, I.C., \& Scheinberg, S. (1992). Elitists, risk-takers, and rugged individualists? An exploratory analysis of cultural differences between entrepreneurs and nonentrepreneurs. Journal of Business Venturing, 7(2), 115-135.

Morris, M., \& Lewis, P. (1991). Entrepreneurship as a significant factor in societal quality of life. Journal of Business Research, 23(1), 21-36.

Nasurdin, A.M., Ahmad, N.H., \& Lin, C.E. (2009).Examining a Model of Entrepreneurial Intention Among Malaysians Using SEM Procedure. European Journal of Scientific Research, 33(2), 365373.

Nunnally, J. C. (1978). Psychometric theory ( $2^{\text {nd }}$ ed.). New York: McGraw-Hill.

Pack, S. J. (2000). Review of De Vecchi, Entrepreneurs, institutions and economic change: the economic thought of J.A. Schumpeter. Brookfield Vt: Edward Elgar.

Reynolds, P. D. (1987). New firms: Societal contributions versus survival potential. Journal of Business Venturing, 2(3), 231-246. 
Roomi. M.A. (2005). Women Entrepreneurs in Pakistan: Profile, Problems, and Policy Recommendations, paper presented at 51st ICSB Conference, Washington, D. C., USA, June.

Shane, S., Kolvereid, L., \& Westhead, P. (1991). An exploratory examination of the reasons leading to new firm formation across country and gender (Part 1). Journal of Business Venturing, 6(6), 431446.

Schoof, U. (2006). Stimulating Youth Entrepreneurship: Barriers and incentives to enterprise start-ups by young people. International Labor Office SEED Working Paper No. 76, Geneva, (Switzerland).

Wong, M., \& Choo, S. (2006). Entrepreneurial intention: triggers and barriers to new venture creations in Singapore. Singapore Management Review, Vol 28(2). Pp 47-64.

\section{Appendix}

Table 5.1

Reliability Analysis

\begin{tabular}{|l|l|}
\hline Variable & Cronbach's Alpha \\
\hline Entrepreneurial Knowledge & 0.86 \\
\hline Professional Attraction & 0.89 \\
\hline Social Valuation & 0.64 \\
\hline Entrepreneurial Capacity & 0.84 \\
\hline Entrepreneurship Intention & 0.85 \\
\hline Entrepreneurial Education & 0.88 \\
\hline
\end{tabular}

Table 5.2

Descriptive Statistics

\begin{tabular}{|l|r|r|r|r|}
\hline & \multicolumn{1}{|c|}{ Minimum } & \multicolumn{1}{c|}{ Maximum } & \multicolumn{1}{c|}{ Mean } & \multicolumn{1}{c|}{ Std. Deviation } \\
\hline Exp & .00 & 1.00 & .3031 & .46033 \\
Age & 19.00 & 32.00 & 21.9781 & 1.49067 \\
Gender & .00 & 2.00 & .6125 & .50063 \\
Father_edu & 5.00 & 14.00 & 12.1375 & 2.73715 \\
Father_emp & .00 & 1.00 & .6125 & .48794 \\
Father_selfemp & .00 & 1.00 & .2156 & .41190 \\
Father_unemp & .00 & 1.00 & .1750 & .38056 \\
EK_1 & 1.00 & 7.00 & 3.9806 & 1.42605 \\
PA_1 & 1.00 & 7.00 & 4.6775 & 1.63611 \\
SV_1 & 1.20 & 7.00 & 4.2325 & 1.13809 \\
EC_1 & 1.00 & 7.00 & 4.2651 & 1.29871 \\
EI_1 & 1.00 & 7.00 & 4.2615 & 1.74219 \\
EE_1 & 1.00 & 7.00 & 4.7881 & 1.37400 \\
N & 320 & & & \\
\hline
\end{tabular}


Table 5.3

Regression Output

\begin{tabular}{|l|r|r|r|}
\hline $\begin{array}{l}\text { Independent } \\
\text { Variables (a) }\end{array}$ & $\begin{array}{c}\text { Beta } \\
\text { Coefficents }\end{array}$ & Std. Errors & t-Values \\
\hline (Constant) & -1.286 & 1.198 & -1.073 \\
\hline Exp & -.078 & .147 & -.533 \\
\hline Age & .026 & .051 & .501 \\
\hline Gender & .611 & .146 & 4.196 \\
\hline Father_edu & .004 & .026 & .150 \\
\hline Father_emp & -.160 & .193 & -.830 \\
\hline Father_selfemp & .243 & .227 & 1.068 \\
\hline EK_1 & -.006 & .055 & -.107 \\
\hline PA_1 & .430 & .051 & 8.414 \\
\hline SV_1 & -.117 & .065 & -1.792 \\
\hline EC_1 & .456 & .058 & 7.863 \\
\hline EE_1 & .251 & .058 & 4.333 \\
\hline
\end{tabular}

a. Dependent Variable: EI_1

$$
\mathrm{R}=.74 \quad \mathrm{R}-\text { Square }=\mathbf{. 5 5 6}
$$

Table 5.4

Pearson Correlation

\begin{tabular}{|l|l|l|l|l|l|l|}
\hline & EK_1 & PA_1 & SV_1 & EC_1 & EE_1 & EI_1 \\
\hline EK_1 & 1 & - & - & - & - \\
\hline PA_1 & $.331^{* *}$ & 1 & - & - & - & - \\
\hline SV_1 & $.351^{* *}$ & $.261^{* *}$ & 1 & - & - & - \\
\hline EC_1 & $.162^{* *}$ & $.406^{* *}$ & $.161^{* *}$ & 1 & - & - \\
\hline EE_1 & $.317^{* *}$ & $.437^{* *}$ & $.133^{*}$ & $.173^{* *}$ & 1 & - \\
\hline EI_1 & $.224^{* *}$ & $.613^{* *}$ & .080 & $.528^{* *}$ & $.436^{* *}$ & 1 \\
\hline
\end{tabular}

Notes:

Sample Size $=320$

*. Correlation is significant at the 0.05 level (2- tailed).

$* *$. Correlation is significant at the 0.01 level (2-tailed). 
